\title{
Is entrepreneur's photo a crucial element in a crowdfunding webpage?
}

\author{
Xin Wang, Huaxin Wang ${ }^{*}$, Yu Zhao \\ Department of Business Administration, Shandong Institute of Commerce and Technology, \\ Jinan, China \\ *Corresponding author: Huaxin Wang, PhD, Assistant Professor, wanghx112@163.com
}

\begin{abstract}
This study investigates the impact of entrepreneur's photo used in a crowdfunding webpage on investor's initial trust, and further, the impact of initial trust on perceived risk and investment intention as well. Laboratory experiments were used to collect data. Results show that entrepreneur's photo is a significantly positive predictor of investor's initial trust belief. Further, investor's initial trust exerts a significantly negative influence on perceived risk; however, initial trust exerts a non-significant influence on investment intention. In addition, perceived risk is a significantly negative predictor of crowdfunding investment intention.
\end{abstract}

Key words: crowdfunding; entrepreneur's photo;initial trust; perceived risk

\section{Introduction}

Recently, crowdfunding has received increasing attention from both research and practice fields. As an evolving field, precisely academic definition of crowdfunding is hardly to be established by far. In this study, crowdfunding is defined as an Internet-based service, through which entrepreneurs could get monetary support by drawing on small contributions from the crowd all over the world (E. M. Gerber and J.Hui ${ }^{1}$, E. Mollick ${ }^{2}$ ).

In line with ${ }^{1}$, individuals may be motivated to fund a project by several reasons such as receiving creative products, helping others, supporting causes and so on; however, they may also be discouraged by the sense of distrust in the entrepreneurs. Hence, a big challenge for entrepreneurs is to engender investor's sense of initial trust by the information delivered by a project presentation. In addition, individual's perceived risk of the project may also be one of crucial barriers of positive decision making. Thus, for crowdfunding entrepreneurs, the avoidance of perceived risk should be another challenge.

Although many elements might exert influences on the formation of initial trust in crowdfunding, this study focuses on the role of entrepreneur's photos presented in a project page. Such a research clue, to some extent, is derived from the study Anderson and Saxton ${ }^{3}$ that reveals the association between borrower's online images and lenders trust beliefs in the context of loan-based crowdfunding.

Drawn upon a dataset of the non-profit lending website (e.g., kiva.org), findings of ${ }^{3}$ might be hardly advisable for other crowdfunding settings. In particular, in order to increase the trust sense of lenders, most borrowers in kiva.org are willing to present personal photos. Differently, in the context of reward-based crowdfunding, a project description is usually placed first to convey information cues relating to products or services. Simultaneously, 
entrepreneur's photo seems not a must-have, because not all reward-based crowdfunding projects demonstrate entrepreneur relevant images.

In this case, could we assert that entrepreneur's photo is not a significant predictor of the trustworthiness of a project in the context of reward-based crowdfunding? To our knowledge, there is lack of relevant studies to address this question. This study attempts to fill the gap by investigating the associations among entrepreneur's photos, investor's initial trust, perceived risk and investment intention.

\section{Hypothesis}

Although some entrepreneurs may repeatedly solicit funds for specific products via crowdfunding projects, more others would raise money through one-off projects. Hence, it is hard for investors to be well acquainted with entrepreneurs before they make investment decision. In this case, the reason why investors are willing to support unfamiliar entrepreneurs might be attributable to trust (R. C. Mayer et al. $\left.{ }^{4}\right)$; more accurately, initial trust (D. H. McKnight et al. ${ }^{5}$ ).

In line with ${ }^{5}$, initial trust refers to investor's trust in an unfamiliar entrepreneur, whom should not have transaction experiences with investors before. Normally, less familiar with entrepreneurs might lead to psychological obstacles during the investment decision-making process ( $\mathrm{X}$. Hu et al. ${ }^{6}, \mathrm{~F}$. P. Karimov et al. ${ }^{7}$ ). Thus, the engendering of initial trust belief should be critical in crowdfunding investment.

Among the information cues delivered by a project presentation, entrepreneur's image might be an available trust-inducing information cue. In fact, according to social presence theory, entrepreneurs' facial images are significant social presence cues, which, to a certain extent, could be interpreted as signals for trustworthiness (K. Aldiri et al. ${ }^{8}$ ).

Previous studies on e-commerce have examined the effects of visual cues on the formation of trust beliefs and reported inspirational findings. For example, the study ${ }^{8}$ investigated and reported that vendor's photographs could be regarded as available trust-inducing signals that may contribute to the formation of consumer's trust sense in e-commerce transactions. Furthermore, the study ${ }^{3}$ examined the persuasive effects of entrepreneur-related images in the context of online peer-to-peer microfinance and revealed that micro-entrepreneurs' loanrequest images indeed play a significant role on supporters' perceptions of trustworthiness. Certainly, there are also different conclusions on the roles of visual cues. For example, findings of $J$. Riegelsberger ${ }^{9}$ showed that vendor-related visual cues hardly exert influences on the formation of consumer's online trust belief.

Anyway, in the context of crowdfunding, we believe entrepreneur's image a stimuli of investors' emotive systems, which is expected contributing to the formation of investor's sense of initial trust. Hence, we hypothesize the following relation:

H1: A project presentation with entrepreneur's photos exerts a significantly higher influence on the formation of individual's initial trust belief than a project presentation without entrepreneur's photos.

Being an Internet-based service, crowdfunding could hardly provide a safe enough environment for participants. From a perspective of investors, they generally make investment 
decisions upon relatively limited information cues conveyed by a project presentation. In this premise, investors may easily form uncertainty or risk perceptions ( $P$. A. Pavlou et al. ${ }^{10}$ ).

Theoretically, perceived risk is commonly associated with individual's feeling of uncertainty and undesirable consequences of engaging in an activity (D. F. Cox and S. U. Rich ${ }^{11}$ ). Previous studies have repeatedly reported the negative impacts of perceived risk on individual's behavioural intention (e.g., S. Glover and I Benbasat ${ }^{12}$ ). Predictively, perceived risk may also be a significant barrier on positive decision making in crowdfunding settings.

Many instruments might be used to alleviate perceived risk. This study highlights the riskreduction role of initial trust. In reality, the dispelling effect of trust on perceived risk has been frequently studied by many researchers (e.g., A. I. Nicolaou and D. H. McKnight ${ }^{13}$ ). In this study, we hypothesize initial trust would lead to a low level of perceived risk. Thus, we hypothesize the following relations:

H2: Individual's initial trust in a project entrepreneur has significantly negative effect on his or her perceived risk.

H3: Individual's perceived risk has significantly negative impact on investment intention.

In line with the trust building model ${ }^{5}$, consumer's initial trust in the vendor is a significantly positive predictor of online behavioural intentions. Actually, findings of ${ }^{5}$ have obtained strongly empirical supports from studies on e-commerce (e.g. K. Aldiri et al. ${ }^{8}$ and G. Kim ${ }^{14}$ ). Similarly, investor's initial trust in entrepreneur is expected having positive effects on crowdfunding investment intention. Thus, the following association has been hypothesized:

H4: Individual's initial trust in a project entrepreneur has significantly positive effect on his or her investment intention.

\section{Methodology}

\subsection{Experiment design}

Two groups of two experimental project pages each were designed and ran to collect data. These two groups of project pages were designed to solicit funds for a multi-functional USB (Fig.1) and a ring mouse (Fig.2), respectively. In each group of experimental projects, one project demonstrated entrepreneur with photo and textual narration, while the other project did not show any information relating to entrepreneur at all. In total, we had four experimental conditions. In order to ensure a fair comparison, we employed a same layout and applied same media types for the two groups of project pages.

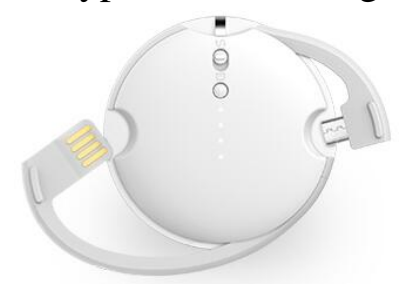

Fig.1- Multi-functional USB

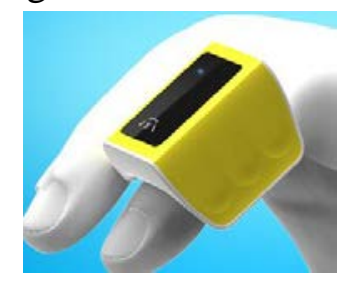

Fig.2 - Ring mouse

\subsection{Experimental subjects}

A total of 114 subjects were recruited from China. Subjects were voluntary to participate in the study. They were randomly assigned to the four experimental conditions, with 27 29 people in each condition. 


\subsection{Measurement}

In the post-experiment questionnaire, measurement items of investment intention were derived from $R$. East ${ }^{15}$. Items for perceived risk were adapted from ${ }^{14}$. Items for Initial trust were derived from ${ }^{5,6}$. All items have been modified to fit into the crowdfunding settings. 7point Likert scales were used for measuring all items.

\section{Data analysis and result}

\subsection{Demographic characteristics}

The experimental subjects were Chinese young people with the range of age being 17 to 23 (average $=19.76$, standard deviation $=0.78$ ). The gender distribution consisted of 73 female (64\%) and 41 male (36\%). There is no significant difference in gender and age distribution across the eight experimental sessions.

\subsection{Effects of initial trust on perceived risk and investment intention}

Partial Least Squares (PLS) path modelling method was used to test the hypothesized associations among initial trust, perceived risk and investment intention. The reliability of variables were tested by examining whether cross loadings greater than 0.7 . All item loadings exceed 0.7 ; hence, indicating adequate reliability.

Then, the convergent validity was examined by checking for the Cronbach's alpha and the composite reliability (CR) of latent variables. Since the Cronbach's alpha and the CR for all the latent variables exceeded 0.7 (Table 1), convergent validity was established. Next, since the squared roots of AVEs were over corresponding correlations, discriminant validity established.

Table 1- Convergent validity and discriminant validity

\begin{tabular}{|l|c|c|l|l|l|}
\hline & Cronbach's alpha & $\begin{array}{c}\text { Composite } \\
\text { reliability }\end{array}$ & Initial trust & Perceived risk & Investment intention \\
\hline Initial trust & 0.961 & 0.968 & 0.914 & & \\
\hline Perceived risk & 0.805 & 0.885 & -0.0962 & 0.847 & \\
\hline Investment intention & 0.941 & 0.955 & 0.1043 & -0.4486 & 0.899 \\
\hline
\end{tabular}

The path strength and significance of hypothesized relations were tested as well. Results indicate that initial trust exerts significantly negative influences on investor's perceived risk $(\mathrm{p}<.05)$; thus, H2 was supported. Further, perceived risk was revealed a significantly negative predictor of investment intention $(\mathrm{p}<.001)$. Hence, H3 was also supported. However, initial trust reports a positive but not significant impact on investment intention; thus, H4 was not supported in this study.

\subsection{Effects of using entrepreneur's photo on initial trust}

Analysis of variance (ANOVA) was conducted to check the impacts of applying entrepreneur's photo in a project presentation on investor's initial trust. Results shown in Table 2 indicated that entrepreneur's photo exerts a significant influence $(\mathrm{p}<.001)$.

Table 2 - ANOVA result of the effect of entrepreneur's photo on initial trust

\begin{tabular}{|l|l|l|l|l|l|}
\hline Source & df & Summary square & Mean square & $\mathrm{F}$ & Sig. \\
\hline Entrepreneur's photo & 1 & 483.3 & 483.3 & 1199 & $<.000 * * *$ \\
\hline
\end{tabular}


Further, post hoc analysis was conducted to reveal how entrepreneur's photo exerts influences. Based on Tukey Honestly Significant Difference (HSD) test, results indicate that investor's initial trust were significantly higher when he/she faced with a project having entrepreneur's photo rather than that without entrepreneur's photo; thus, H1 was supported (Table 3).

Table 3 - Tukey HSD test results of entrepreneur's photo on initial trust

\begin{tabular}{|c|c|c|c|c|c|}
\hline \multirow{2}{*}{$\begin{array}{l}\text { Basic group } \\
\text { (B) }{ }^{1}\end{array}$} & \multirow{2}{*}{$\begin{array}{l}\text { Compared group } \\
(\mathrm{C})^{2}\end{array}$} & \multirow{2}{*}{$\begin{array}{l}\text { Mean difference } \\
\qquad(\mathrm{D}=\mathrm{C}-\mathrm{B})^{3}\end{array}$} & \multirow[b]{2}{*}{ Sig. } & \multicolumn{2}{|c|}{ 95\% confidence interval } \\
\hline & & & & Lower bound & Upper bound \\
\hline $\begin{array}{l}\text { [1] WITHOUT } \\
\text { entrepreneur's photo } \\
\text { (mean: } 2.321 \text { ) }\end{array}$ & {$[2]$} & 2.059 & $.000^{* * *}$ & 1.942 & 2.176 \\
\hline $\begin{array}{l}\text { [2] WITH } \\
\text { entrepreneur's photo } \\
\text { (mean: } 4.380 \text { ) }\end{array}$ & {$[1]$} & -2.059 & $.000^{* * *}$ & -2.176 & -1.942 \\
\hline \multicolumn{6}{|c|}{$\begin{array}{l}\text { Notes: } * * * p<.001 \\
\text { (1) (B): Basic group. Report the mean of initial trust from a project WITHOUT and WITH entrepreneur's photo, respectively. } \\
\text { (2) }(C): \text { Compared groups. For each basic group, there is one different mean of initial trust. } \\
\text { (3) }(D=C-B): \text { Mean difference between compared group and basic group. }\end{array}$} \\
\hline
\end{tabular}

\section{Discussions}

\subsection{Theoretical implication}

This study indicates that the usage of entrepreneur's photo in a project presentation exerts significantly positive influence on the improvement of investor's initial trust beliefs in the context of crowdfunding. This finding is consistent with the studies ${ }^{3,8}$, in which photos were regarded as available social presence signals. In this case, our study contributes to the literature of social presence by providing empirically supporting evidence in the context of crowdfunding.

Further, this study reports that initial trust has significantly negative effect on perceived risk. That is, trust could be regarded as an available risk reliever in crowdfunding. Such a result is similar with the findings of ${ }^{13}$ in e-commerce settings. Hence, to some extent, our study contributes to the literature of trust and perceived risk.

In addition, this study reveals that initial trust exerts a positive but non-significant influence on crowdfunding investment intention. This result is inconsistent with the trust building model ${ }^{5}$ and other studies on e-commerce. A plausible explanation for such a result may be due to the one-off transaction mechanism of crowdfunding. Differently with the repeated transaction mode in e-commerce, it may be hard for investors to enhance their initial trust beliefs in a specific entrepreneur in subsequent funding activities. In this way, initial trust may be an available risk reliever, but yet a significantly positive predictor of investment intention.

\subsection{Practical implication}

This study also generates some implications for crowdfunding practitioners. In particular, it indicates that the usage of entrepreneur's photo in a project presentation facilitates the formation of investor' initial trust in the entrepreneur; and further, initial trust is a significant risk reliever in the context of crowdfunding. Hence, it may be a key point for entrepreneurs to present photos in their project presentations. Additionally, from the perspective of website designers, they should provide high level of customization features for crowdfunding creators to present their projects, especially, permitting to demonstrate entrepreneur's photos. 


\section{Conclusions}

In summary, this study explores whether entrepreneur's photo is a significant influencing factor in the context of crowdfunding. In particular, it examines the impact of entrepreneur's photo used in a project presentation on investor's initial trust; and further, the impact of initial trust on perceived risk and investment intention as well. Results show that entrepreneur's photo is a significantly positive predictor of investor's initial trust belief. Further, investor's initial trust belief exerts a significantly negative influence on perceived risk; however, it exerts a non-significant influence on investment intention. In addition, perceived risk is indeed an obstacle of crowdfunding investment intention.

\section{Acknowledgement}

This work was supported by the Research Foundation of Shandong Provincial Department of Education under Grant No. J16WF40

\section{References}

1. E. M. Gerber, J. Hui, Crowdfunding: Motivations and deterrents for participation, ACM Transactions on Computer-Human Interaction (TOCHI) 2 (6) (2013) 34-34.

2. E. Mollick, The dynamics of crowdfunding: An exploratory study. Journal of Business Venturing 29(1) (2014) 1-16.

3. K. B. Anderson, G. D. Saxton, Smiles, Babies, and Status Symbols, The persuasive effects of image choices in small-entrepreneur crowdfunding requests, International Journal of Communication 10 (2016) 1764-1785.

4. R. C. Mayer, J. H. Davis and F. D. Schoorman, An integrative model of organizational trust, Academy of Management Review 20(3) (1995) 709-734.

5. D. H. McKnight, V. Choudhury and C. Kacmar, The impact of initial consumer trust on intentions to transact with a web site: a trust building model, The Journal of Strategic Information Systems 11(3) (2002) 297-323.

6. X. Hu, G. Wu, Y. Wu and H. Zhang, The effects of Web assurance seals on consumers' initial trust in an online vendor: A functional perspective, Decision Support Systems 48(2) (2010) 407-418.

7. F. P. Karimov, M. Brengman and L. Van Hove, The effect of website design dimensions on initial trust: a synthesis of the empirical literature, Journal of Electronic Commerce Research 12(4) (2011) 272-301.

8. K. Aldiri, D. Hobbs and R. Qahwaji, The human face of e-business: engendering consumer initial trust through the use of images of sales personnel on e-commerce web sites, International Journal of E-Business Research 4(4) (2008) 58-78. 
9. J. Riegelsberger, M. A. Sasse and J. D. McCarthy, Shiny happy people building trust? photos on e-commerce websites and consumer trust. In: SIGCHI conference on Human factors in computing systems (2003).

10. P. A. Pavlou, H. Liang and Y. Xue, Understanding and mitigating uncertainty in online exchange relationships: a principal-agent perspective, MIS Quarterly 31(1) (2007) 105136.

11. D. F. Cox, S. U. Rich, Perceived risk and consumer decision-making: The case of telephone shopping, Journal of Marketing Research 1(4) (1964) 32-39.

12. S. Glover, I. Benbasat, A comprehensive model of perceived risk of e-commerce transactions, International Journal of Electronic Commerce 15(2) (2010) 47-78.

13. A.I. Nicolaou, D. H. McKnight, Perceived information quality in data exchanges: Effects on risk, trust, and intention to use, Information Systems Research 17(4) (2006) 332-351.

14. G. Kim, B. Shin and H. G. Lee, Understanding dynamics between initial trust and usage intentions of mobile banking, Information Systems Journal 19(3) (2009) 283-311.

15. R. East, Investment decisions and the theory of planned behaviour, Journal of Economic Psychology 14(2) (1993) 337-375. 